\title{
Investigation of the Stage Performance and Flow Fields in a Centrifugal Compressor with a Vaneless Diffuser
}

\author{
Ahti Jaatinen-Värri, Aki Grönman, Teemu Turunen-Saaresti, and Jari Backman \\ Institute of Energy, Lappeenranta University of Technology, P.O. Box 20, 53851 Lappeenranta, Finland \\ Correspondence should be addressed to Ahti Jaatinen-Värri; ahti.jaatinen@lut.fi \\ Received 2 April 2014; Accepted 26 June 2014; Published 23 July 2014 \\ Academic Editor: Paolo Pennacchi \\ Copyright (C) 2014 Ahti Jaatinen-Värri et al. This is an open access article distributed under the Creative Commons Attribution \\ License, which permits unrestricted use, distribution, and reproduction in any medium, provided the original work is properly \\ cited. \\ The effect of the width of the vaneless diffuser on the stage performance and flow fields of a centrifugal compressor is studied \\ numerically and experimentally. The diffuser width is varied by reducing the diffuser flow area from the shroud side (i.e., pinching \\ the diffuser). Seven different diffuser widths are studied with numerical simulation. In the modeling, the diffuser width $b / b_{2}$ is \\ varied within the range 1.00 to 0.50 . The numerical results are compared with results obtained in previous studies. In addition, two \\ of the diffusers are further investigated with experimental measurement. The main finding of the work is that the pinch reduces \\ losses in the impeller associated with the tip-clearance flow. Furthermore, it is shown that a too large width reduction causes the \\ flow to accelerate excessively, resulting in a highly nonuniform flow field and flow separation near the shroud.
}

\section{Introduction}

Centrifugal compressors have been used and studied for decades, and they play a substantial role in a variety of processes in which continuous gas flow is required. Even though centrifugal compressors are widespread and have been the subject of numerous studies, many aspects of compressor aerodynamics and their highly complex flow are not yet fully understood.

Possible narrowing of the vaneless diffuser after the impeller exit (i.e., a pinch) is an example of a feature that requires further investigation. A pinch is a commonly used design practice to ensure a larger stall margin and thus a wider operating range. However, the precise effects of a pinch on the diffuser flow fields, and thus on the overall stage performance, are still somewhat unclear.

Previous studies by the authors indicate that implementing a pinch increases the design operating point efficiency and pressure ratio [1-4]. In the previous tests, the diffuser width $b / b_{2}$ was varied from 1.0 to 0.806 , and the best design was found to be one with an approximately $15 \%$ narrowing in the diffuser, with the next-best design being one with almost $20 \%$ narrowing. In the literature, there are papers indicating that excessive pinches (width reduction around $40 . .50 \%$ ) lead to deteriorated compressor performance [5-7]. Studies would thus seem to indicate that moderate pinches are beneficial to the compressor stage performance, whilst excessive pinches are not.

In this paper, the effects of the diffuser width on the flow fields in the vaneless diffuser of a centrifugal compressor are investigated with CFD. In the numerical studies, the diffuser width is $b / b_{2}$ is varied within the range 1.00 to 0.50 . In addition to the numerical work, two diffuser widths $\left(b / b_{2}=\right.$ 0.75 and 0.5 ) are also studied experimentally. The numerical results are compared to the experimental results.

It is shown in this work that the stage efficiency imprvement found with moderate pinches is a result of a reduction in losses associated with tip-clearance and the tip-clearance flow. In addition, the results further show that excessive width reductions cause the flow to accelerate disproportionately, resulting in a nonuniform flow field and flow separation, which in turn increase the losses.

\section{Studied Designs}

A total of seven different diffusers of varying width were investigated with numerical simulation, and two diffusers 
TABLE 1: Studied designs.

\begin{tabular}{ccc}
\hline$b / b_{2}$ & CFD & TESTED \\
\hline 1.00 & $\mathrm{X}$ & Tested in [1-4] \\
0.91 & $\mathrm{X}$ & Tested in [1-4] \\
0.85 & $\mathrm{X}$ & Tested in [1-4] \\
0.81 & $\mathrm{X}$ & Tested in [1-4] \\
0.75 & $\mathrm{X}$ & $\mathrm{X}$ \\
0.60 & $\mathrm{X}$ & $\mathrm{X}$ \\
0.50 & $\mathrm{X}$ & \\
\hline
\end{tabular}

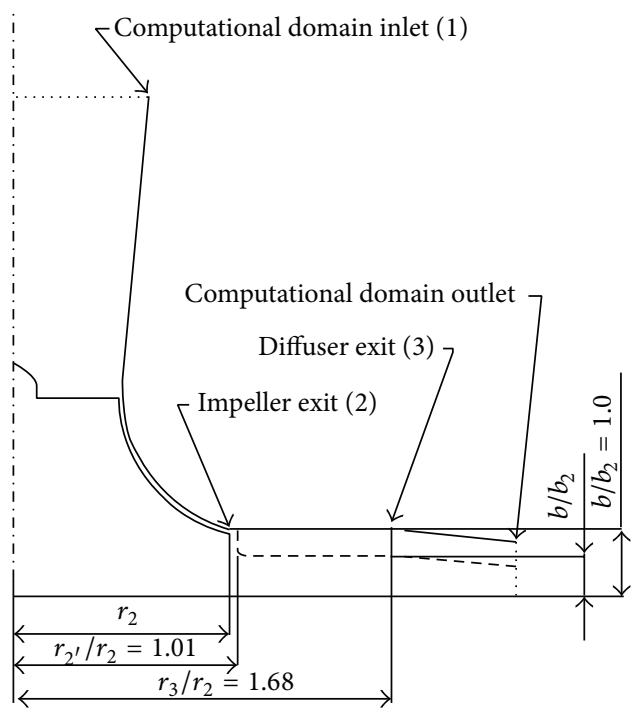

FIGURE 1: Schematics of the design, showing the unpinched (solid line) and pinched (dashed line) designs.

were studied experimentally. In the numerical study, the diffuser width $b / b_{2}$ was varied from 1.00 to 0.50 , and in the experimental study, the diffuser widths were 0.75 and 0.50 . All other design parameters remained constant. The diffuser outlet radius ratio $r_{3} / r_{2}$ was 1.68 .

In all cases studied, the width reduction was implemented only on the shroud side because this has been found to be more beneficial than dividing between the shroud and hub $[2$, 3]. The width reduction began at the radius ratio $r_{2^{\prime}} / r_{2}$ of 1.01 . Width reduction consisted of a straight wall perpendicular to the shroud wall and a rounding. The studied designs are summarized in Table 1 , and a schematic view of the setup is presented in Figure 1.

\section{Numerical Methods}

The computational domain and the structured surface grid in the impeller and diffuser are presented in Figures 2 and 3 , respectively. The calculation domain has 11 blocks for the unpinched geometry and 12 blocks for the pinched geometries. Before the impeller inlet, there is an inlet section to represent the actual inlet cone of the test rig. The tip clearance is also modeled. As the volute is not modeled, there is a short exit section after the actual vaneless diffuser.

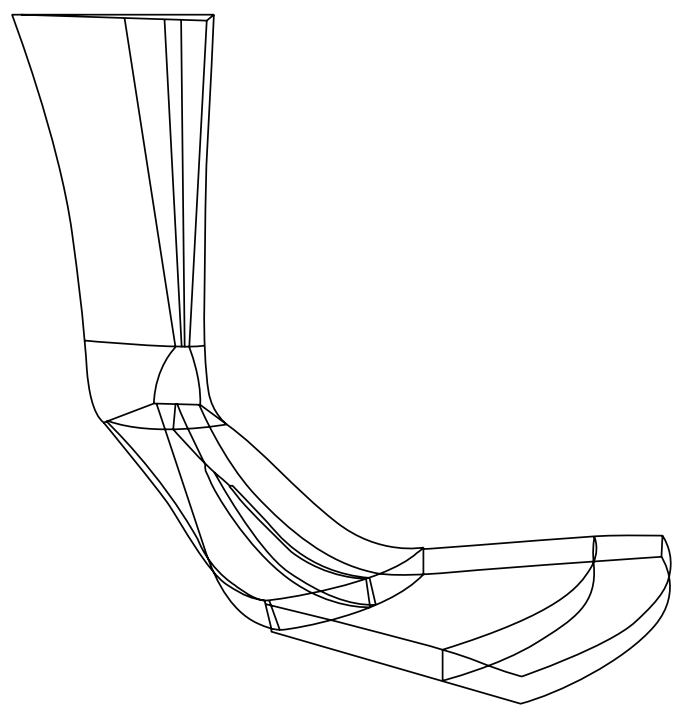

FIgURE 2: The computational domain.

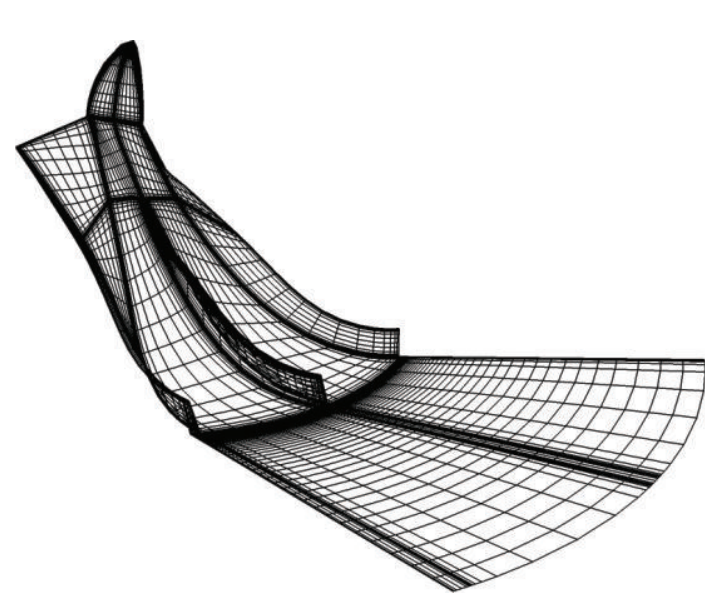

FIGURE 3: Surface grid in the impeller and diffuser. For the sake of clarity, the shroud is not shown and only every other grid line is visible.

The vaneless diffuser is a parallel wall, and the exit section between the diffuser exit and the computational domain outlet has a constant cross-sectional flow area. This approach was chosen to ensure that the outlet boundary would not affect the results at the diffuser outlet. This is especially important in simulations in which reversed flow is present at the diffuser outlet. Oh and Agrawal [8] and Oh et al. [9] have previously used contraction after the vaneless diffuser to partly eliminate the reversed flow associated with lower flows.

The Navier-Stokes solver Finflo is used in this study. This multigrid solver employs the finite-volume method for spatial discretization and uses a constant specific heat capacity at constant pressure. The fluid is modeled as an ideal gas (air).

Roe's flux difference splitting method [10] is used for inviscid fluxes and thin-layer approximation for viscous fluxes. Primary flow variables and conservative turbulent variables are solved with a MUSCL type approach. More detailed information about Finflo and different numerical 
methods can be found, for example, in the study of Siikonen [11].

The turbulence is modeled with a $k-\omega$-SST turbulence model [12] without the wall functions. Therefore, the used grids have nondimensional wall distance values close to unity in most of the blade and diffuser surfaces. Higher values are found in some sections of the blade surfaces.

A frozen rotor approach is employed to model the interface between the stationary parts and the rotor. This quasisteady method has been successfully used previously in the compressor studies of Jaatinen [13], Röyttä et al. [14], and Turunen-Saaresti et al. [15].

Uniform momentum and total enthalpy distributions are defined as the inlet boundary conditions. Constant static pressure distribution is used as the boundary condition at the outlet. During the simulations, the convergence is monitored by following the mass flow difference between the inlet and outlet, the L2-norms of density, momentum in all three directions, and energy residuals. The simulation is considered to be converged when the residuals and mass flow difference are stable.

\section{Grid Dependency}

A grid dependency study was performed at the beginning of the simulations. Three grids: low, medium, and high, with approximately 1.3, 2.1, and 3.2 million cells, respectively, were tested. Differences in the stage total-to-total pressure ratio, stage total-to-total efficiency, diffuser static pressure rise coefficient, and diffuser total pressure loss coefficient were studied.

The performance parameters were calculated with mass flow averaged values. The stage total-to-total efficiency is defined as

$$
\eta_{\mathrm{t}, 1-5}=\frac{T_{t 1}\left(\pi_{\mathrm{tt}}^{R / c_{p}}-1\right)}{T_{5 t}-T_{t 1}},
$$

the diffuser total pressure loss coefficient as

$$
K_{\mathrm{pr}}=\frac{p_{t 2}-p_{t 3}}{p_{t 2}-p_{2}}
$$

and the diffuser static pressure rise coefficient as

$$
C_{\mathrm{pr}}=\frac{p_{3}-p_{2}}{p_{t 2}-p_{2}} .
$$

The stage efficiency and pressure ratio, nondimensionalised with the efficiency and pressure ratio of the medium grid, are presented in Figure 4, and the diffuser pressure recovery and loss coefficients in Figure 5. From the figures it can be seen that the tested variables (pressure ratios, efficiencies, pressure loss coefficients, and pressure recovery coefficients) hardly change when the cell count is increased from 2.1 to 3.2 million cells. The grid with least cells gives somewhat different values than the other two grids. In addition, as the simulation results can be compared with experimental results, it is thus concluded that 2.1 million cells are sufficient to provide accurate and valid results.

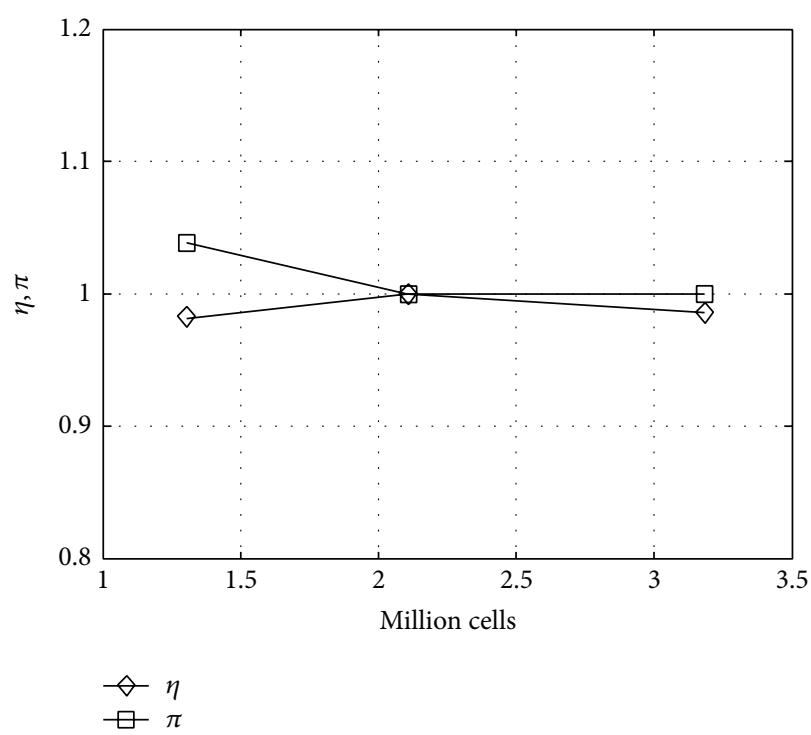

FIGURE 4: Stage efficiencies and pressure ratios with different grids.

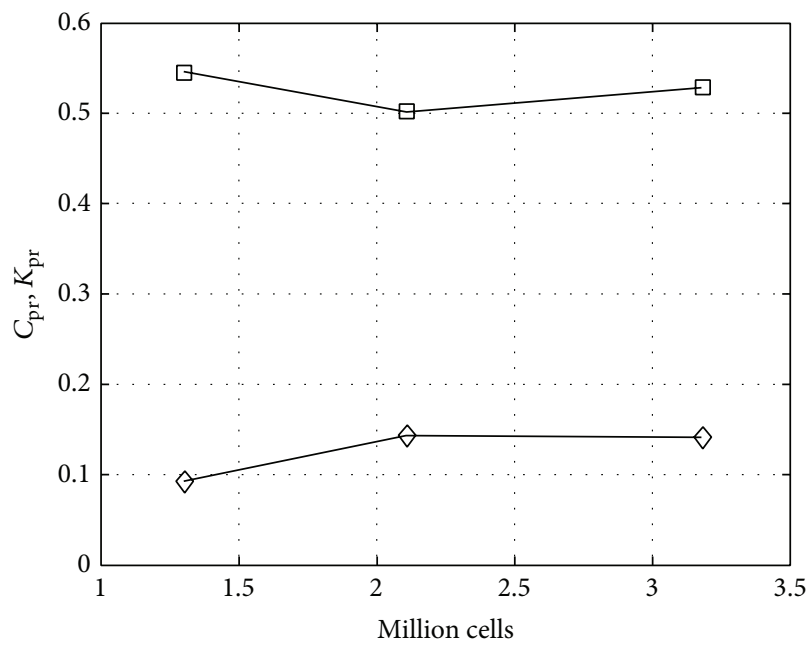

$$
\square C_{\mathrm{pr}}
$$$$
\diamond K_{\mathrm{pr}}
$$

FigURE 5: Diffuser pressure loss and recovery coefficients with different grids.

It must be noted that the above-mentioned 2.1 million cells were used with the unpinched design. For other designs, the grid distribution was kept the same in the diffuser. Therefore, when the diffuser width is reduced, the grid points in the corresponding (axial) direction are reduced accordingly, which ensures that the grid dependency does not change between the cases.

\section{Experimental Setup}

The layout of the test stand is shown in Figure 6. The test stand is open; that is, it intakes atmospheric air and discharges into the atmosphere. The pressures and temperatures are 


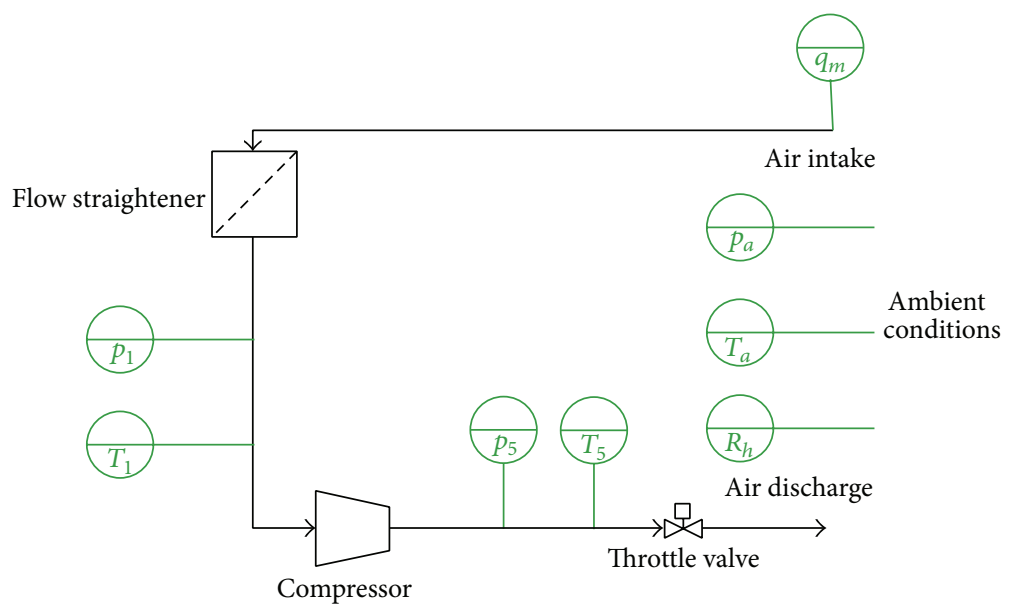

Figure 6: Layout of the test stand.

measured before and after the compressor. In addition, the ambient pressure, ambient temperature, relative humidity, and mass flow are measured. The mass flow is measured with an ISA nozzle, made according to DIN1952 [16], and the instrumentation, measurement procedure, and performance calculations comply with the relevant standards [17-20].

The test compressor is an industrial high-speed, variable speed drive compressor with a design pressure ratio $\pi_{\mathrm{tt}}=$ 1.78. The compressor is equipped with magnetic bearings, and the design specific speed is 0.8 .

The impeller is unshrouded and has 7 full and 7 splitter blades, both with $40^{\circ}$ backsweep. The compressor has a volute designed to cause a constant circumferential pressure distribution at the design operating point.

The maximum relative measurement errors for the mass flow, efficiency, and pressure ratios are $\pm 0.17 \%, \pm 0.47 \%$, and $\pm 0.33 \%$, respectively.

The same test stand, compressor, and methods were also used in previous papers by the authors [1-4].

\section{Results}

6.1. Stage Performance. The measured total-to-total stage efficiencies and pressure ratios are compared to the simulated values in Figures 7 and 8 . It should be noted that the simulated efficiency is calculated with the diffuser exit temperature (stage 3 in Figure 1), and the measured efficiency is calculated with the compressor exit temperature ( $T_{5}$ in Figure 6). The pressure ratios are treated similarly. Furthermore, the efficiencies are nondimensionalised with the measured efficiency of the original, unpinched diffuser.

It can be seen from Figures 7 and 8 that both the pressure ratio and efficiency first increase as the diffuser width reduces. If the width reduction is large enough, both the pressure ratios and efficiencies start to decrease. In this study, the best performance was achieved when the diffuser width $b / b_{2}$ was 0.85 , and the performance started to decrease when the diffuser width was further reduced from $b / b_{2}=0.80$.

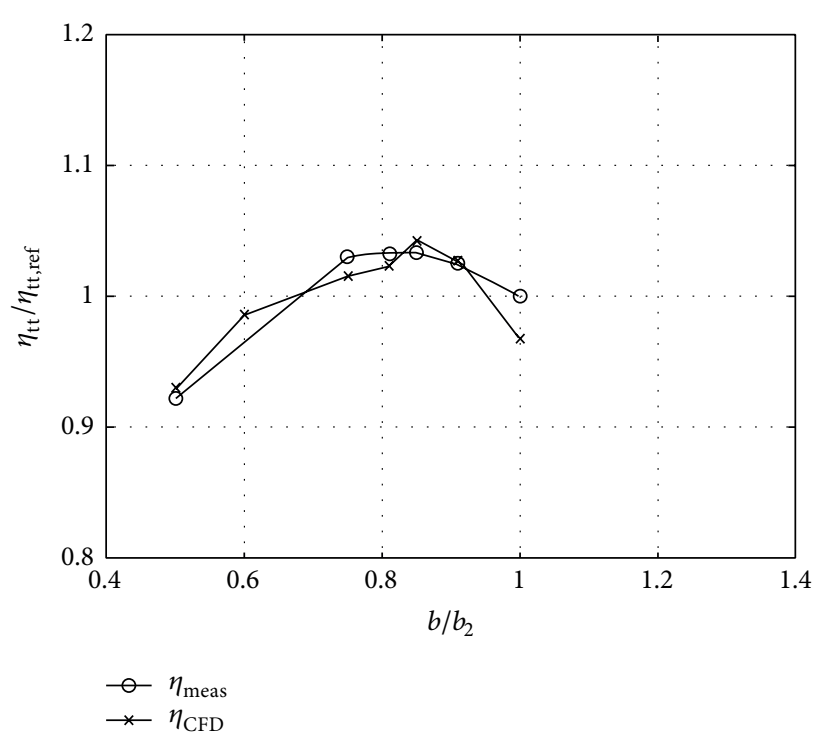

FIGURE 7: Comparision between measured and simulated stage total-to-total efficiencies. The efficiency for each design is taken at the same mass flow.

The CFD results are in good agreement with the experimental results. The total-to-total stage pressure ratio is slightly overpredicted, as the measurements are done with a full stage while the numerical simulations are done without the volute and exit cone. The efficiency is predicted better. Most importantly, the trend is predicted very well, which is a further indication of the reliability of the simulations.

As the diffuser width was reduced, the efficiency and pressure ratio behaved as expected on the basis of the literature survey and previous studies. In previous work by the authors, it was concluded that the pinch reduced the slow flow region that is present at the impeller exit near the shroud. One of the major factors affecting the slow flow region is the tip-clearance flow, which mixes into the flow in the blade passage. Thus, it was speculated that the pinch affects also the 


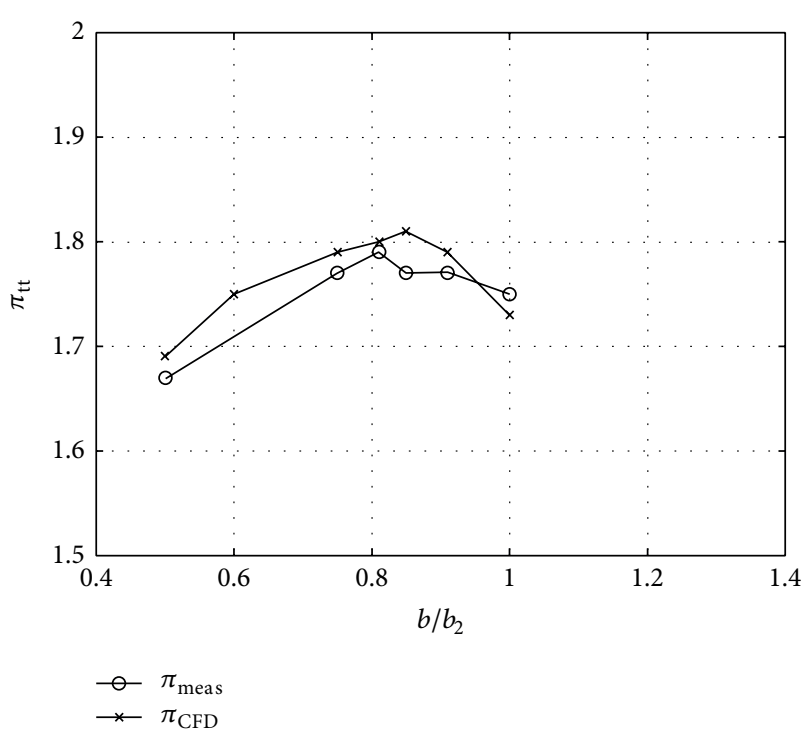

FIGURE 8: Comparison between measured and simulated stage totalto-total pressure ratios. The pressure ratio for each design is taken at the same mass flow.

tip-clearance flow. This is investigated in the following section by studying the numerically predicted flow fields, especially flow fields close to the impeller exit.

6.2. Flow Fields. The entropy fields in the blade passages and at the impeller exit for each modeled case are presented in Figures 13-19. The entropy field in the blade passage is at the same height as the blade tip ${ }^{1}$. The areas of high entropy indicate higher losses which are then seen as lower efficiency. In general, comparing the different cases, first the areas of high entropy decrease when the diffuser is narrowed from the original unpinched design. The smallest areas of high entropy are found when the diffuser width is between 0.85 and 0.91 , and when the diffuser width is decreased further, the areas of high entropy increase. This is in line with observations on how pressure ratio and efficiency behave as a function of the diffuser width, as seen in Figures 7 and 8.

There is a distinct area of high entropy at the impeller exit, near the splitter blade suction side-shroud corner. This area is highly affected by the tip-clearance flow, and losses there occur when the tip-clearance flow mixes with the main flow. The same phenomenon also occurs on the suction side of the full blade, but the effect is more pronounced on the suction side of the splitter blade. Similar results have been found by Schleer and Abhari [21]. Their study concluded that because the tip-clearance flow of the splitter blade interacts with the rotational channel flow, the interaction is stronger, and the occurring slow momentum, high loss region shifts towards the middle of the passage whilst the tip-clearance flow of the full blade stays closer to the shroud $[21,22]$.

Streamlines in the impeller passages and over the blades through the tip clearance gap are presented for the unpinched design in Figure 9. In the figure, the blue streamlines are for the main flow, red for the tip clearance flow over the full

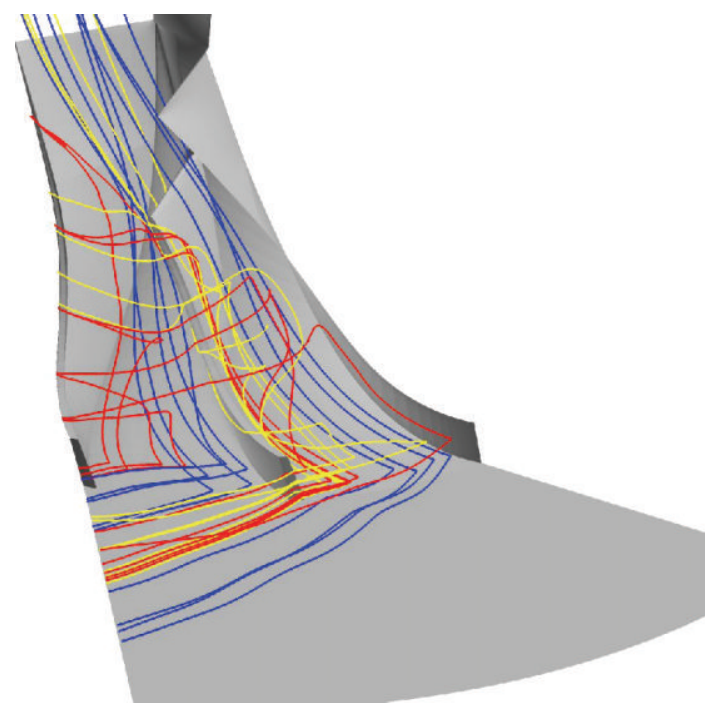

FIgURE 9: Streamlines in the unpinched design. Blue is the main flow, red is the tip clearance flow over the full blade, and yellow is the tip clearance flow over the splitter blade.

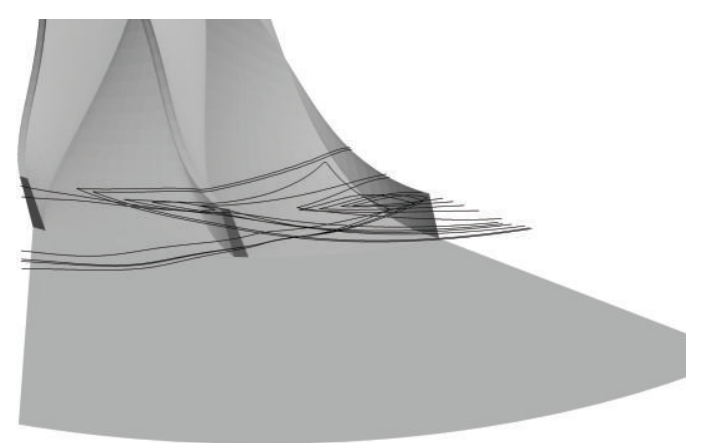

FIgURE 10: Streamlines near the impeller exit in the unpinched design.

blade, and yellow for the tip clearance flow over the splitter blade. The figure shows that part of the tip clearance flow over the full blade mixes into the main flow in the adjacent blade passage, and part of the flow migrates over the splitter blade and mixes into the main flow on the suction side of the splitter blade. This location is also where the tip clearance flow of the splitter blade mixes into the main flow. This explains why the losses are larger on the suction side of the splitter blade than at the suctions side of the full blade.

The streamlines seeded from the diffuser for the unpinched design and the design with the best efficiency $\left(b / b_{2}=0.85\right)$ are shown in Figures 10 and 11. There is a clear difference in the flow patterns. With the unpinched diffuser, there is a clear back flow near the shroud from the diffuser back into the impeller passages. Once the backflow reaches the impeller, the rotation forces the flow over the blades through the tip clearance gaps and on to the suction sides where the flow mixes into the main flow and exits the impeller. With the best pinched design (Figure 11) there is no such backflow from the diffuser. 


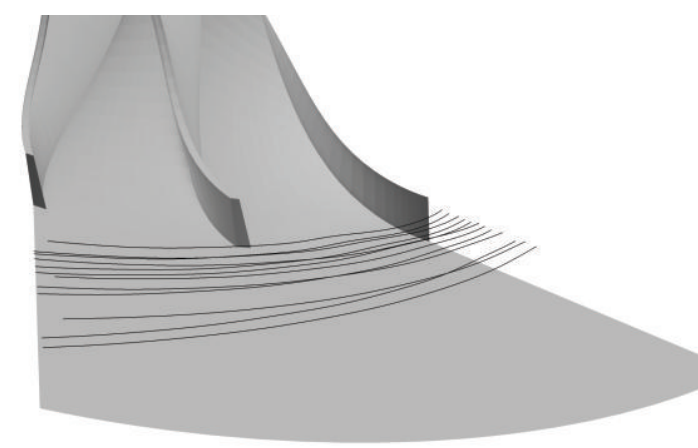

FIGURE 11: Streamlines near the impeller exit $b / b_{2}=0.85$.

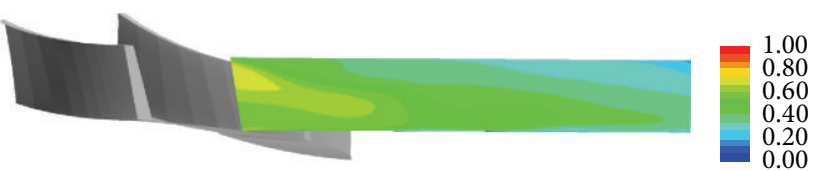

(a)

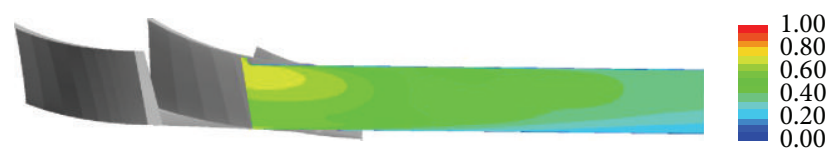

(b)

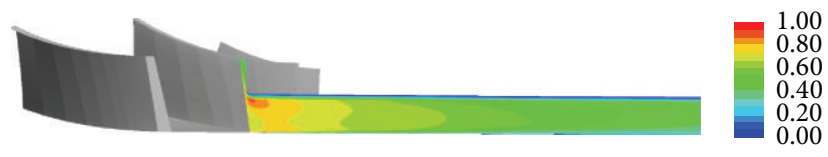

(c)

Figure 12: Absolute Mach number in the diffuser taken in the middle of the flow passage in circumferential direction. Top $b / b_{2}=$ 1.00 , middle $b / b_{2}=0.85$, and bottom $b / b_{2}=0.50$.

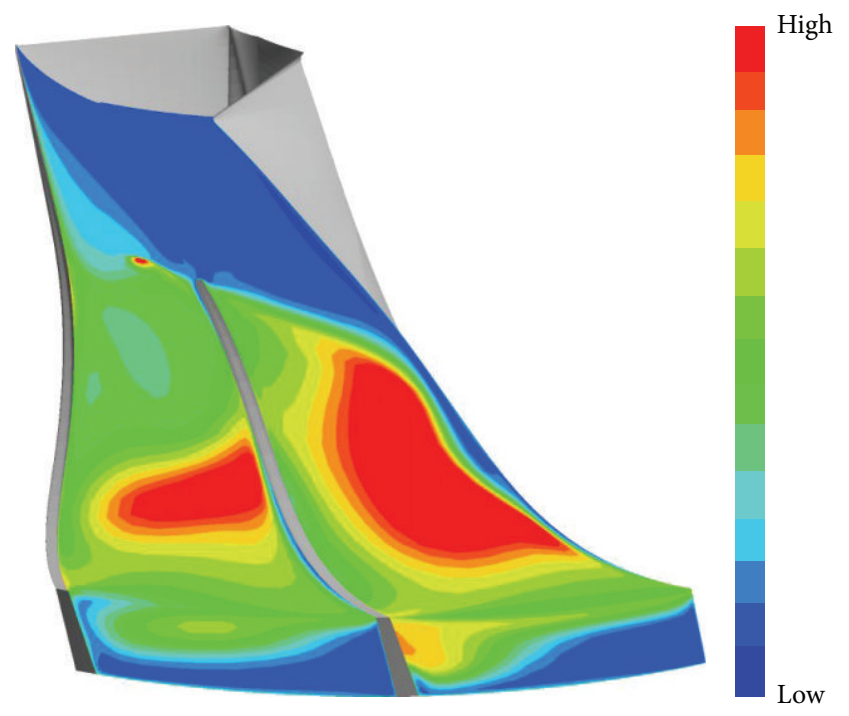

FIGURE 13: $b / b_{2}=1.00$

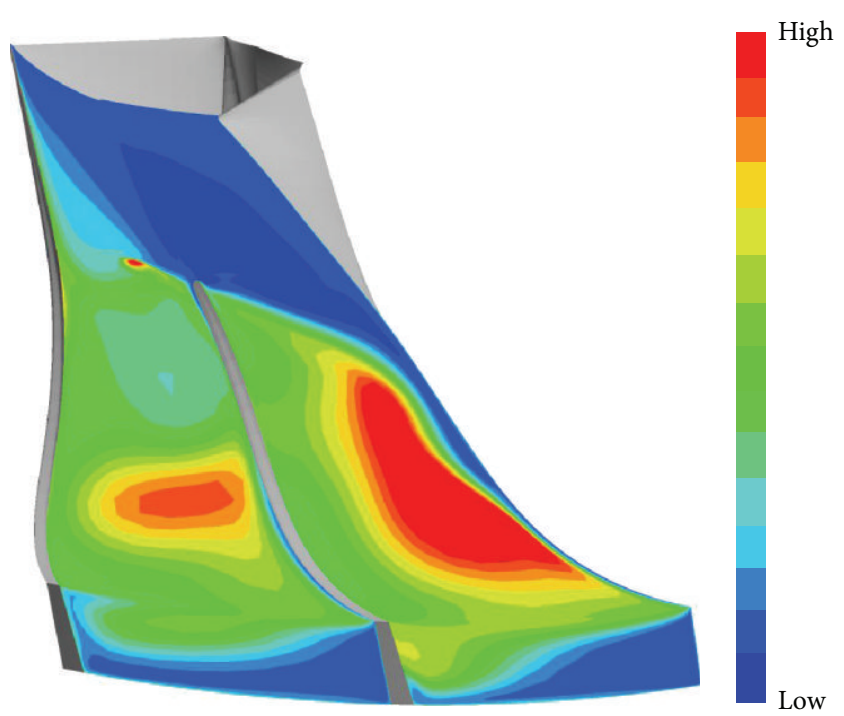

FIGURE $14: b / b_{2}=0.91$

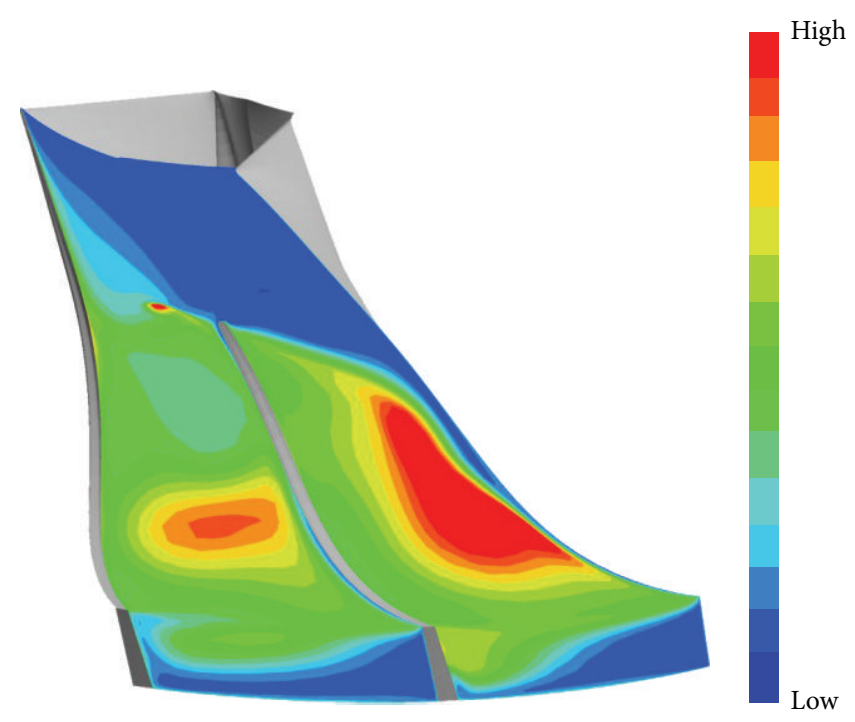

FIGURE $15: b / b_{2}=0.85$.

The absolute Mach number in the diffuser is presented for three designs $\left(b / b_{2}=1.00,085\right.$, and 0.5) in Figure 12. The Mach number distribution is taken from the middle of the flow passage between the full blade and the splitter blade. There are no major differences in the Mach number distributions between the unpinched case and the one with a moderate pinch. A slight acceleration can be seen near the shroud around the pinch. However, this does not considerably increase the nonuniformity of the flow fields, and thus it does not cause additional losses. With the largest pinch, the flow clearly accelerates excessively. At this pinch, the Mach number is closer to unity, and the abrupt acceleration causes the flow to separate near the shroud. The separation is seen as a low Mach number region near the shroud and shows why the largest pinches $\left(b / b_{2}=0.75\right.$ or below $)$ cause a reduction in the stage efficiency. 


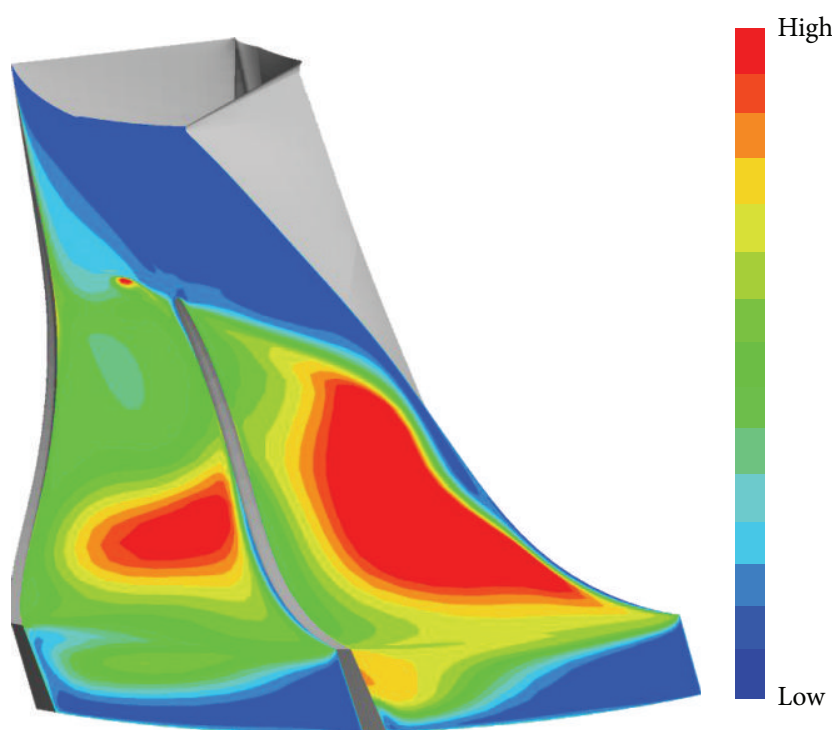

FIGURE $16: b / b_{2}=0.81$

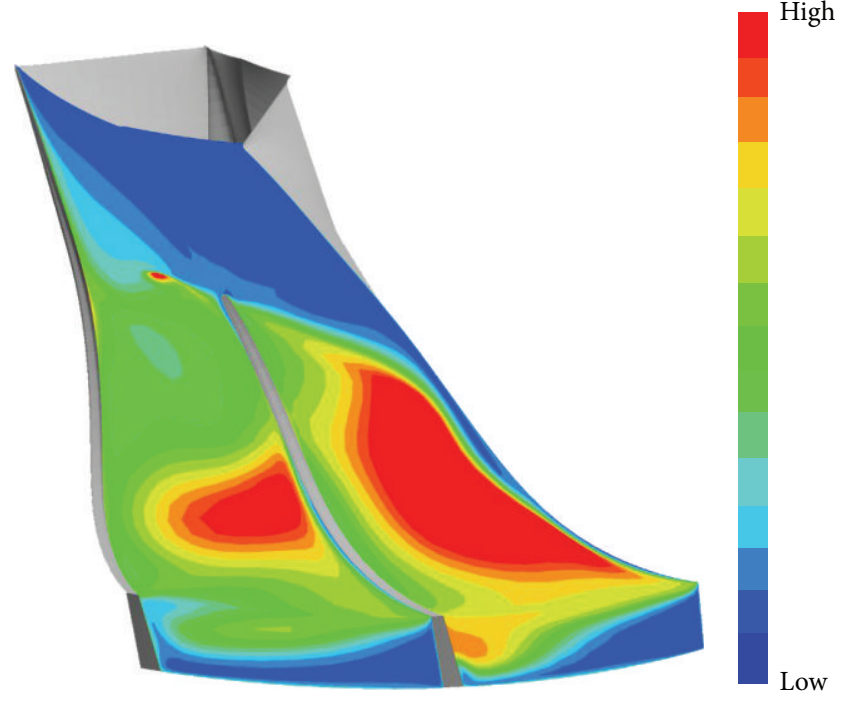

FIGURE $17: b / b_{2}=0.75$.

Entropy fields in the diffuser at a radius ratio $r / r_{2}$ of 1.1 are presented in Figures 20-26. ${ }^{2}$ The well-known impeller exit flow structure (core flows (jets), passage wakes and blade wakes) are still present at this radius, and it is highlighted in Figure 20, as an example.

From Figures 20-26, it can be seen that the blade wakes are less pronounced than the passage wakes; that is, they are almost mixed into the main flow. This is in line with results obtained by Pinarbasi and Johnson [23], who concluded that the blade wakes mix into the main flow faster than the passage wakes. The pinch has an effect on the entropy generation in the diffuser. With moderate pinches the entropy generation in passage wakes (losses) is smaller than with the

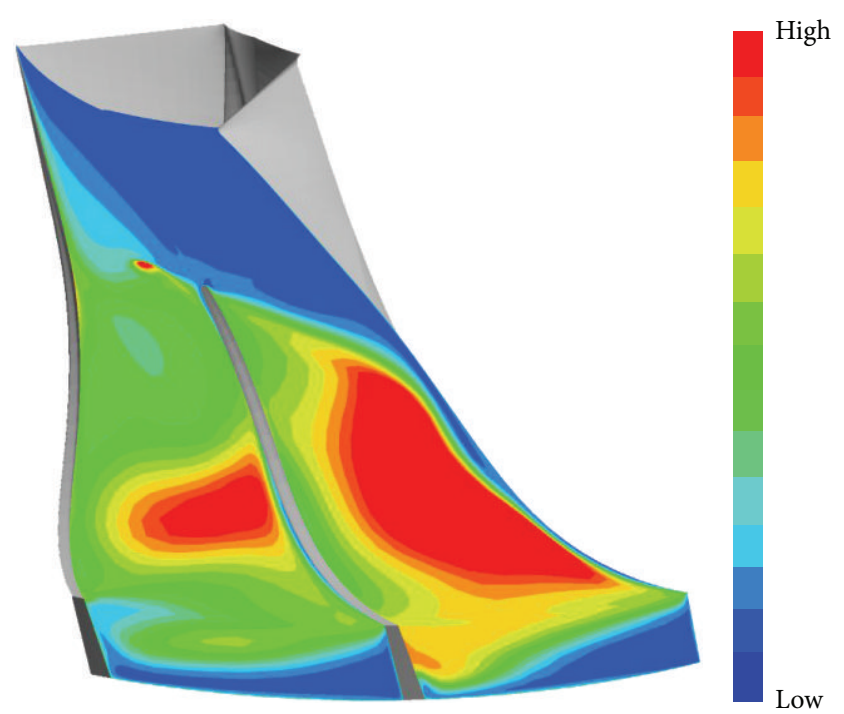

FIGURE $18: b / b_{2}=0.60$.

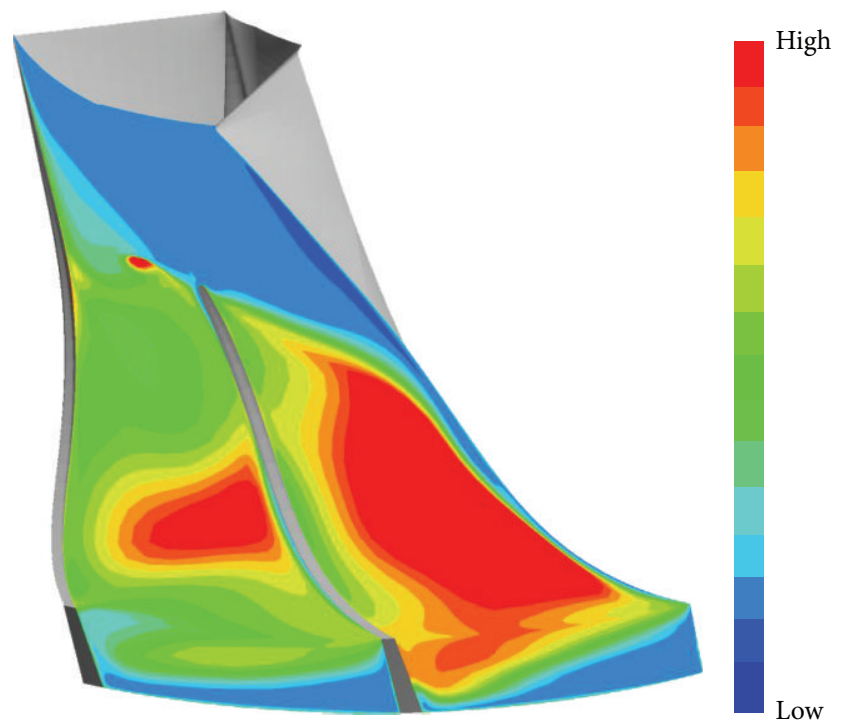

FIGURE 19: $b / b_{2}=0.50$

unpinched design or the designs with a large pinch. The losses in passage wakes are smallest with the designs where $b / b_{2}$ is 0.91 and 0.85 . When the pinch is increased further, the entropy generation (losses) in the passage wakes increases. This is most likely due to the moderate pinches making the flow field more uniform at the impeller exit.

From Figures 20-26, it can further be concluded that the pinch has no effect on the blade wakes. They are almost the same irrespective of the diffuser width. The separation caused by the excessive pinch is clearly seen as a high entropy area close to the shroud. The high entropy separated regions are clearly visible when the diffuser width $b / b_{2}$ is 0.75 or less. 


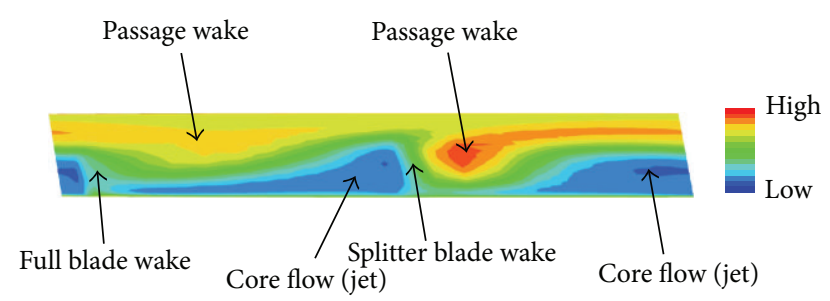

FIgURE $20: b / b_{2}=1.00$.

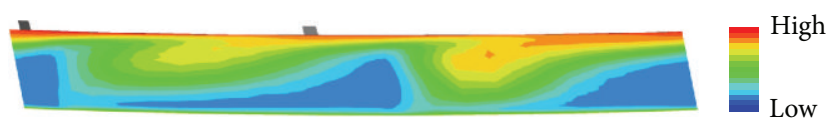

FIGURE 21: $b / b_{2}=0.91$.

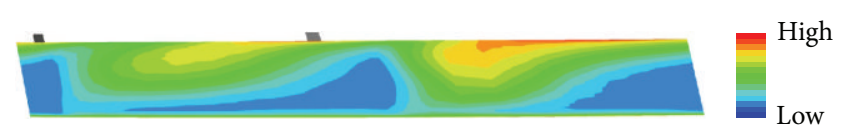

FIGURE $22: b / b_{2}=0.85$.

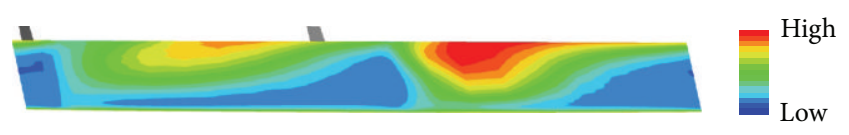

FIGURE 23: $b / b_{2}=0.81$.

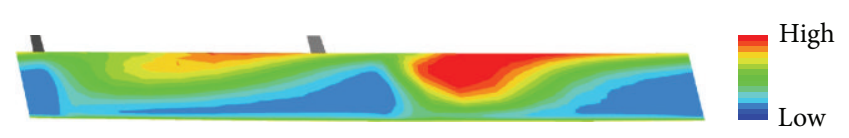

FIGURE $24: b / b_{2}=0.75$.

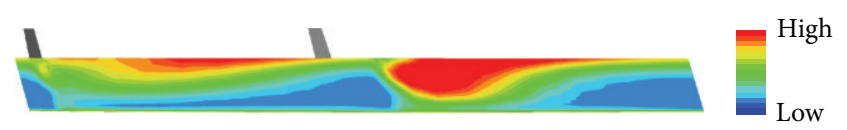

FIGURE 25: $b / b_{2}=0.60$.

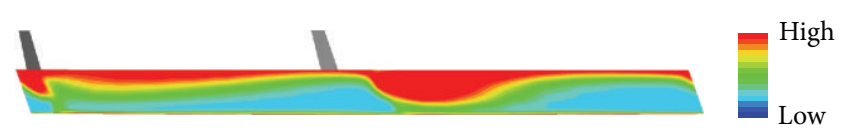

FIGURE $26: b / b_{2}=0.50$.

\section{Discussions and Conclusions}

In this study, seven different vaneless diffusers were studied numerically and two of the vaneless diffusers were studied also experimentally. The simulated overall performance parameters were compared to results measured in this and previous studies. The modeled diffuser widths $b / b_{2}$ were between 1.0 and 0.50 , and the two tested diffuser widths were 0.75 and 0.50 . The Navier-Stokes solver Finflo was used for the simulations, and the turbulence was modeled with a $k-\omega$ SST turbulence model without the wall functions.
In the analysis, the modeled overall performance parameters were first studied. The results clearly show that when the diffuser width is reduced from its original unpinched width $\left(b / b_{2}=1.00\right)$, both the efficiency and pressure ratio increase at first. In this study, a peak occurs when the diffuser width $b / b_{2}$ is 0.85 , after which the efficiency and pressure ratio start to decrease when the diffuser width is further reduced. The simulated performance parameters were compared against the measured ones, and agreement was found to be very good. Furthermore, the behavior of the efficiency and pressure ratio with respect to the diffuser width was as expected on the basis of previous studies and the literature.

In addition to the overall performance of the compressor, the flow fields were also studied. The entropy distributions in the blade passage and at the impeller exit were studied, as were the radial velocity and Mach number distributions in the vaneless diffuser. The main findings of the work can be summarized as follows.

(1) The entropy fields clearly show that the areas of high entropy where losses occur are smaller with the diffusers that showed the highest efficiency and pressure ratios. It can be seen that when a moderate pinch $\left(b / b_{2}=0.85-0.91\right)$ is implemented, the high entropy/high loss areas associated with the tip-clearance flow are smaller. The effect is more pronounced next to the splitter blade, where some of the tip-clearance vortices of the full blade merge into the tip-clearance vortices of the splitter blade and then into the main flow.

(2) The streamlines distributions show that pinches decrease the backflow from the diffuser into the impeller near the shroud. Part of the backflow is due to the tip clearance flow, but the backflow is mainly caused by the well-known jet-wake structure of the impeller exit flow. Eventually, these slow momentum regions mix into the main flow in the diffuser.

(3) The benefits of the pinch are lost with excessive pinches $\left(b / b_{2}=0.75\right.$ or less $)$. The flow fields at the impeller exit become less uniform, which is seen as areas of very high entropy and therefore losses. The increased losses are due to the flow accelerating excessively because of the too large pinch, resulting into the separation of the flow near the shroud. However, the separation might strongly depend on how the pinch is implemented, that is, the pinch shape.

(4) The effects of pinch can be seen also in the diffuser. When the diffuser width is reduced moderately, the entropy generation in the passage wake is smaller than with the unpinched design or if the diffuser width is reduced considerably. As mentioned above this is due to the moderate pinches making the flow field more uniform at the impeller exit. This effect is seen as lower loss generation in the passage wakes in the diffuser. It seems that the pinch has no considerable effect on the mixing of blade wakes. 
Based on this study, it can be concluded that moderate width reductions are beneficial to the compressor stage performance in terms of efficiency and pressure ratio. With the compressor, impeller, and pinch design used in this project, width reductions up to $20 \%$ were beneficial. Further research on other machines is needed to study whether this can be used as a universal design rule.

Furthermore, the shape of the pinch needs to be studied to establish whether or not the shape of the pinch influences the flow fields or the compressor performance. In addition, further research is needed to study if there is an optimum radius at which the pinch should be implemented.

\section{Nomenclature}

\section{Latin Alphabet}

$b$ : $\quad$ Diffuser width, $\mathrm{m}$

$C_{\mathrm{pr}}$ : Diffuser static pressure recovery coefficient

$c_{p}$ : Specific heat capacity, $\mathrm{J} / \mathrm{kgK}$

$K_{\mathrm{pr}}$ : Diffuser total pressure loss coefficient

p: Pressure

$R: \quad$ Specific gas constant, $\mathrm{J} / \mathrm{kgK}$

$T$ : Temperature, $\mathrm{K}$.

\section{Greek Alphabet}

$\eta$ : Efficiency

$\pi$ : Pressure ratio.

\section{Subscripts}

1: Compressor inlet

2: Impeller exit

$2^{\prime}$ : Beginning of the pinch

3: Diffuser exit

5: Compressor outlet

$t$ : Total.

\section{Conflict of Interests}

The authors declare that there is no conflict of interests regarding the publication of this paper.

\section{Endnotes}

1. The entropy fields are taken at the same rotational speed and mass flow for each design, namely the design rotational speed and design mass flow of the original, unpinched design.

2. The entropy fields are taken at the same rotational speed and mass flow for each design, namely the design rotational speed and design mass flow of the original, unpinched design. To highlight the differences between the design, the scale is not the same as in Figures 16-19, hence direct comparison with them is ill-advised.

\section{References}

[1] T. Turunen-Saaresti, A. Grönman, and A. Jaatinen, "Experimental study of pinch in vaneless diffuser of centrifugal compressor," in Proceedings of the ASME Turbo Expo, GT200960162, pp. 1427-1438, Orlando, Fla, USA, June 2009.

[2] A. Jaatinen, A. Grönman, T. Turunen-Saaresti, and P. Röyttä, "Effect of vaneless diffuser width on the overall performance of a centrifugal compressor," Proceedings of the Institution of Mechanical Engineers A: Journal of Power and Energy, vol. 225, no. 5, pp. 665-673, 2011.

[3] A. Jaatinen-Värri, P. Röyttä, T. Turunen-Saaresti, and A. Grönman, "Experimental study of centrifugal compressor vaneless diffuser width," Journal of Mechanical Science and Technology, vol. 27, no. 4, pp. 1011-1020, 2013.

[4] A. Jaatinen-Varri, T. Turunen-Saaresti, P. Roytta, A. Gronman, and J. Backman, "Experimental study of centrifugal compressor tip clearance and vaneless diffuser flow fields," Proceedings of the Institution of Mechanical Engineers A: Journal of Power and Energy, vol. 227, pp. 885-895, 2013.

[5] K. Ludtke, "Aerodynamic tests on centri fugal process compressors: the inuence of the vaneless diffusor shape," Journal of engineering for power, vol. 105, no. 4, pp. 902-909, 1983.

[6] G. Ferrara, L. Ferrari, C. P. Mengoni, M. D. Lucia, and L. Baldassarre, "Experimental investigation and characterization of the rotating stall in a high pressure centrifugal compressor: part II: Inuence of diffuser geometry on stage performance," in Proceedings of ASME Turb o Expo, GT2002-30390, Amsterdam, The Netherlands, June 2002.

[7] A. Cellai, G. Ferrara, L. Ferrari, C. Mengoni, and L. Baldassarre, "Experimental investigation and characterization of the rotating stall in a high pressure centrifugal compressor part I II: inuence of diffuser geometry on stall inception and performance (2nd Im peller Tested)," in Proceedings of the ASME Turbo Expo, vol. GT2003-38390, Atlanta, Ga, USA, June 2003.

[8] J. Oh and G. L. Agrawal, "Numerical investigation of low solidity vaned diffuser performance in a high-pressure centrifugal compressor part I: influence of vane solidity," in Proceedings of the ASME Turbo Expo, pp. 1009-1015, Montreal, Canada, May 2007.

[9] J. S. Oh, C. W. Buckley, and G. L. Agrawal, "Numerical investigation of low solidity vaned diffuser performance in a high-pressure centrifugal compressor part II : influence of vane stagger," in Proceeding s of the ASME Turbo Expo, Berlin, Germany, June 2008.

[10] P. L. Roe, "Approximate Riemann solvers, parameter vectors, and difference schemes," Journal of Computational Physics, vol. 43, no. 2, pp. 357-372, 1981.

[11] T. Siikonen, "An application of Roe's flux-difference splitting for $k-\epsilon$ turbulence model," International Journal for Numerical Methods in Fluids, vol. 21, no. 11, pp. 1017-1039, 1995.

[12] F. R. Menter, "Two-equation eddy-viscosity turbulence models for engineering applications," AIAA journal, vol. 32, no. 8, pp. 1598-1605, 1994.

[13] A. Jaatinen, Performance improvement of centrifugal compressor stage with pinched geometry or vaned diffuser [Ph.D. thesis], Lappeenranta University of Technology, Lappeenranta, Finland, 2009.

[14] P. Röyttä, A. Grönman, A. Jaatinen, T. Turunen-Saaresti, and J. Backman, "Effects of different blade angle distributions on 
centrifugal compressor performance," International Journal of Rotating Machinery, vol. 2009, Article ID 537802, 9 pages, 2009.

[15] T. Turunen-Saaresti, A. Reunanen, and J. Larjola, "Computational and experimental study of pinch on the performance of a vaneless diffuser in a centrifugal compressor," Journal of Thermal Science, vol. 15, no. 4, pp. 306-313, 2006.

[16] DIN 1952, 1971, Durchuflmessung mit genormten Dusen, Blenden und Venturid usen, Deutsches Institut fur Normunge.V.

[17] ASME PTC 10, ASME Power Test Codes, Compressors and Exhausters, The American Society of Mechanical Engineering, 1965.

[18] ISO 5389, Turbocompressors-Performance Test Code, International Stardardization Organization, 1992.

[19] VDI 2045 Part 1, “Abnahme-und Leistungsversuche an Verdichtern, Versuchsdurchfuhrung und Garantievergleich (Acceptance and Performance Test on Tur bo Compressors and Displacement Compressors, Test Procedure and Comparison with Guaranteed Values)," Verein Deutscher Ingenieure, 1993.

[20] Verein Deutscher Ingenieure, VDI 2045 Part 2. Abnahmeund Le istungsversuche an Verdichtern, Grund lagen und Beispiele (Acceptance and Performance Test on Turbo Compressors and Displacement Compressors, Theory and Examples), 1993.

[21] M. Schleer and R. S. Abhari, "Clearance effects on the evolution of the flow in the vaneless diffuser of a centrifugal compressor at part load condition," Journal of Turbomachinery, vol. 130, no. 3, Article ID 031009, 9 pages, 2008.

[22] M. Schleer, S. J. Song, and R. S. Abhari, "Clearance effects on the onset of instability in a centrifugal compressor," Journal of Turbomachinery, vol. 130, no. 3, Article ID 031002, 11 pages, 2008.

[23] A. Pinarbasi and M. W. Johnson, "Detailed flow measurements in a centrifugal compressor vaneless diffuser," Journal of Turbomachinery, vol. 116, no. 3, pp. 453-461, 1994. 

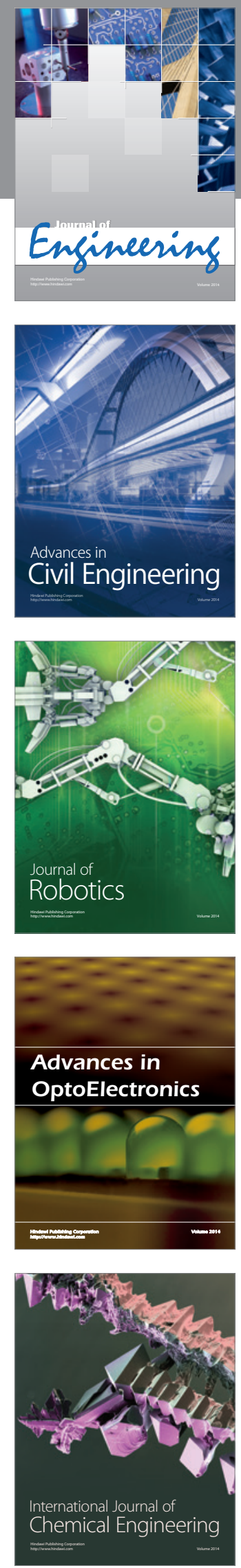

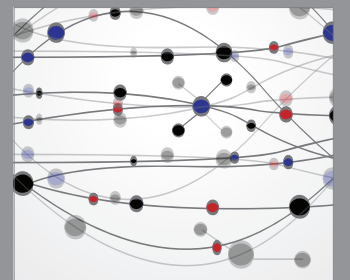

The Scientific World Journal
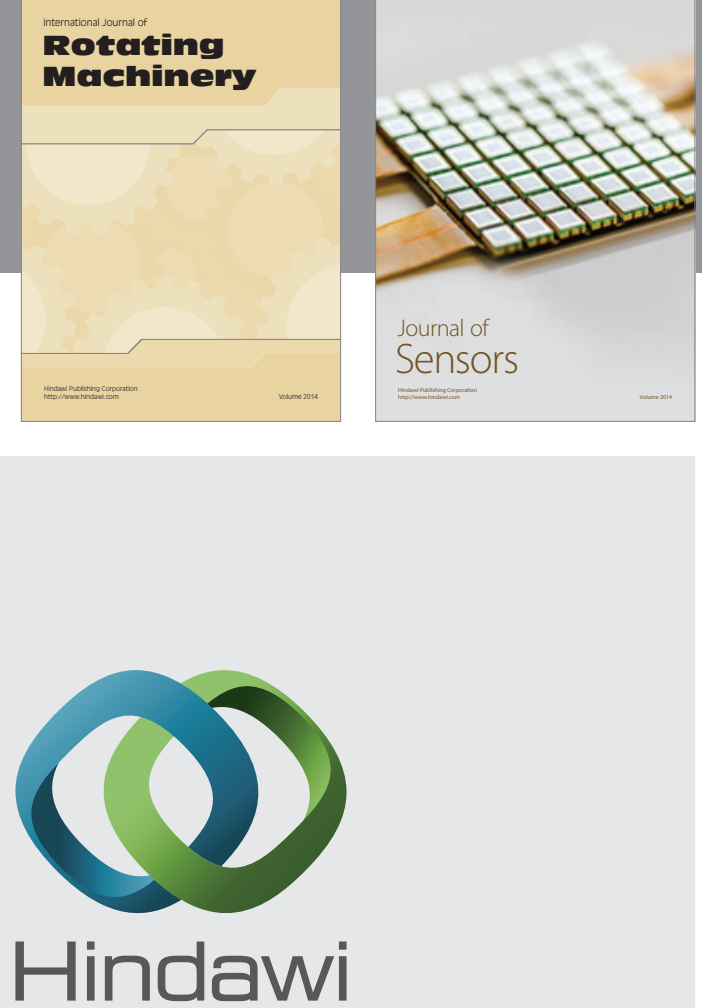

Submit your manuscripts at http://www.hindawi.com
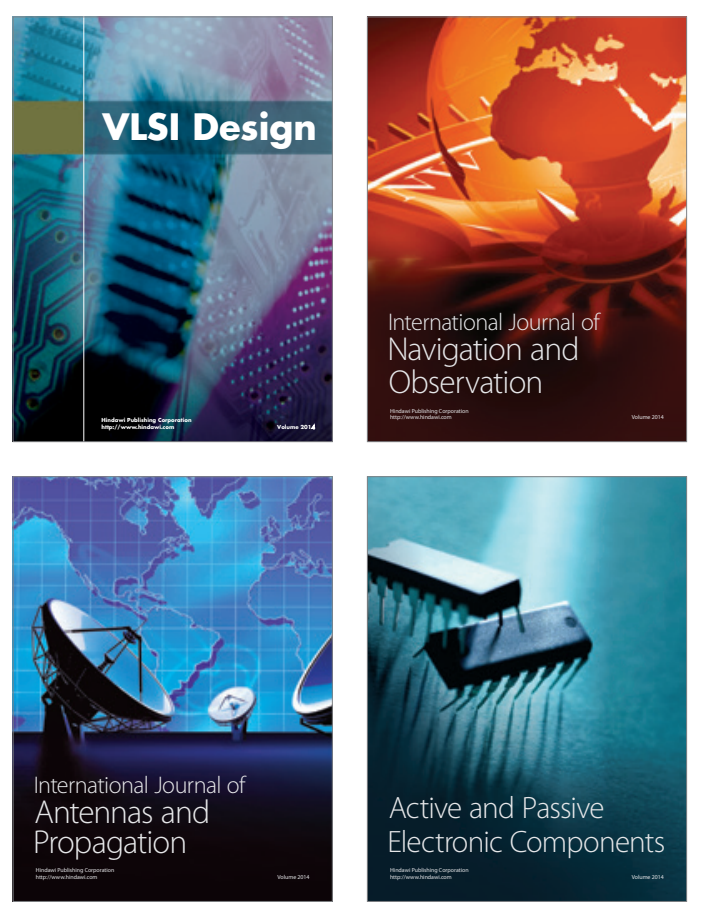
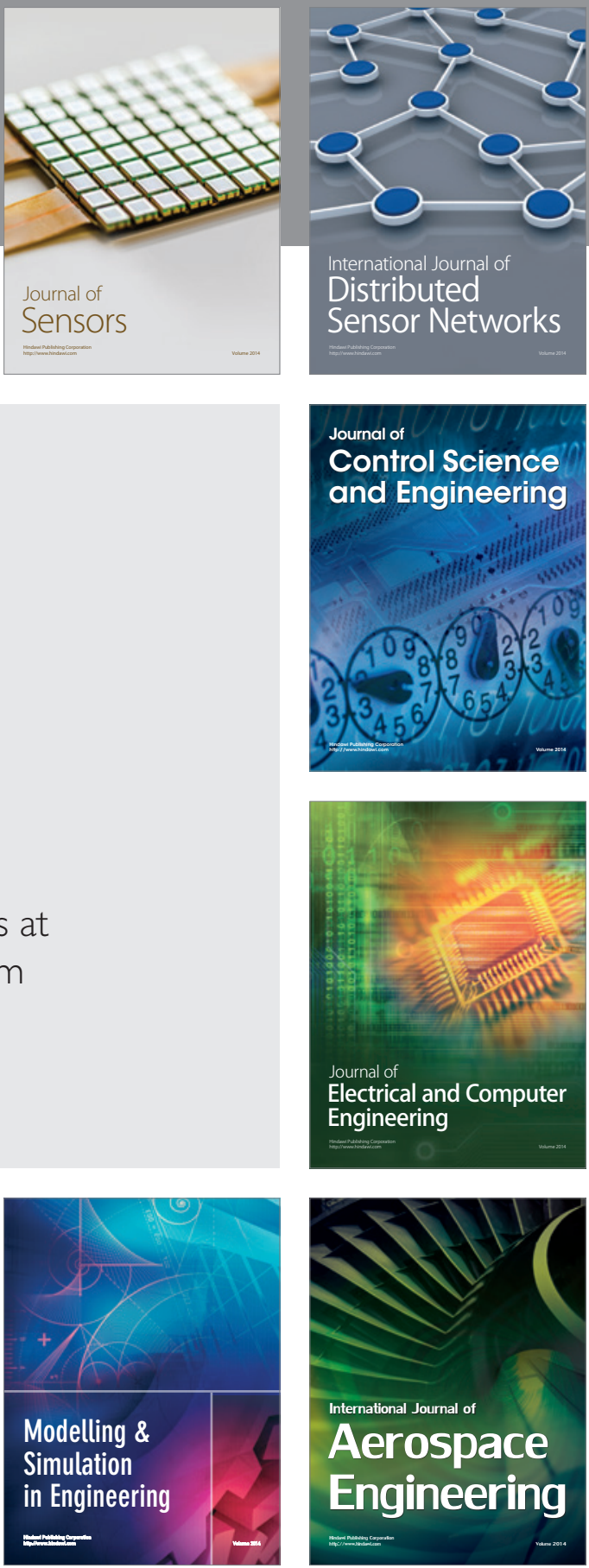

Journal of

Control Science

and Engineering
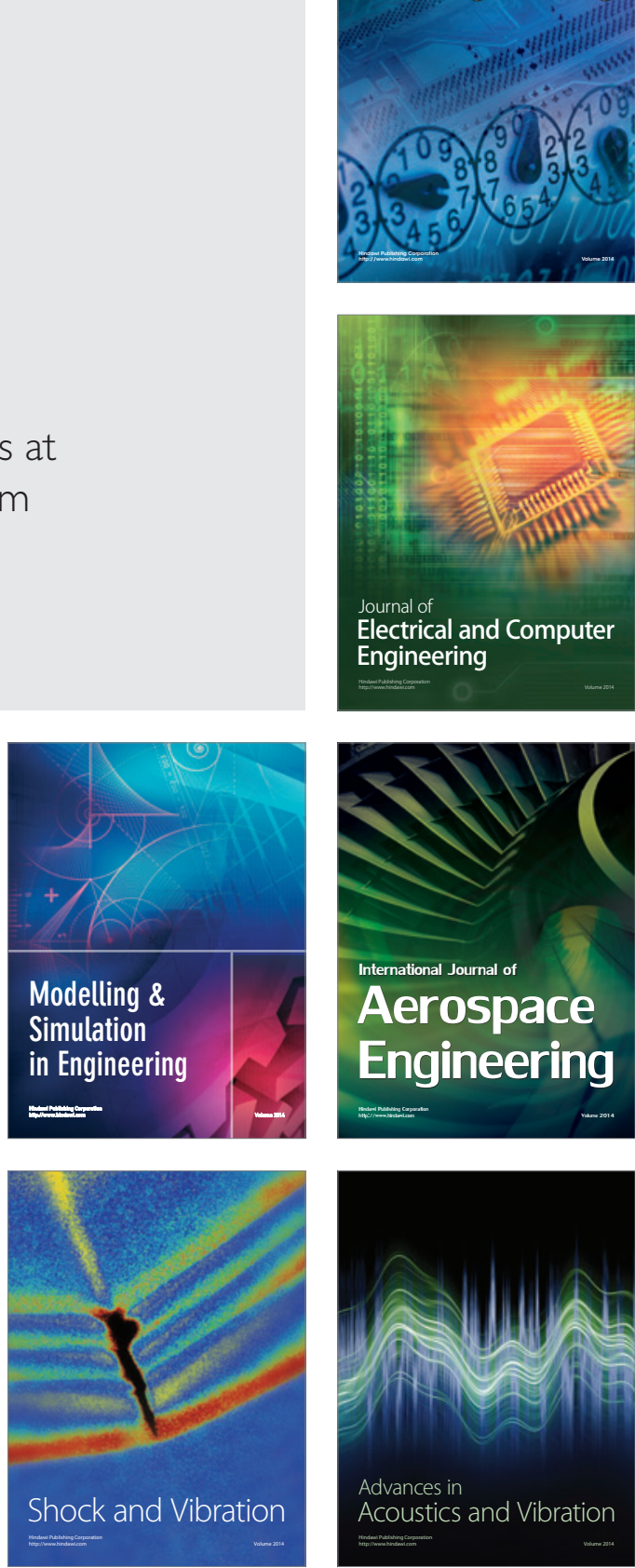